\title{
Gene Expression in Thyroxin-Induced Metamorphosing Axolotl Hearts
}

Dipak K Dube ${ }^{1,2^{\star}}$, Aruna Narshi ${ }^{1}$, Matthew D. McLean ${ }^{2}$, Syamalima Dube ${ }^{1}$ and Bernard J. Poiesz ${ }^{1}$

${ }^{1}$ Department of Medicine, SUNY Upstate Medical University, USA

2Department of Developmental Biology, SUNY Upstate Medical University, USA

\section{Introduction}

The Mexican axolotl (Ambystoma mexicanum) is a unique model to study vertebrate heart development for several reasons. In addition to the wild-type animal, there is also an embryonic lethal condition caused by a homozygous recessive mutation in cardiac gene " $c$ " $[1,2]$. These mutant embryonic hearts do not contract, are deficient in tropomyosin, and lack organized myofibrils [3,4], making them an excellent model to study the process of cardiac myofibrillogenesis $[5,6]$. In contrast to most other model organisms currently being utilized, axolotl embryos are comparatively large ( $2 \mathrm{~mm}$ diameter), hence, they can be studied with relative ease. Being amphibians, axolotl embryos mature externally within jelly coats. Therefore, unlike using mammalian embryos, it is unnecessary to sacrifice the parent. Moreover, an average of a hundred axolotl embryos are produced from a single spawning and these embryos develop relatively slowly which is useful for studying vital developmental stages of interest [7]. In fact the timing of developmental stages of interest may be controlled to some extent, as the rate of development for these poikilothermic animal embryos is temperature dependent [8].

Moving from an aquatic environment to a terrestrial environment will expose an animal to different atmospheric pressure and respiration requirements. An advantage the axolotl has over other amphibians such as Xenopus for studying metamorphosis is its neoteny. In Xenopus, metamorphosis is the natural developmental pathway. The Mexican axolotl is an inducible obligate neotene, meaning it rarely metamorphoses in the wild and retains larval features, such as gills, into sexually mature adulthood. However, it may be induced to metamorphose by thyroid function manipulation [9]. It is thought that there is a deficiency in secretion of thyroid-stimulating hormone (TSH), possibly due to a poor response of the pituitary to thyrotrophic releasing hormone, which does not allow the axolotl to naturally metamorphose [9]. However, it can be experimentally induced to metamorphose using tri-iodo-L-thyronine (T3), thyroxin (T4) or TSH $[10,11]$ to become a terrestrial amphibian. Once metamorphosis is induced, the axolotl goes through several morphological changes, culminating in complete metamorphosis in around 18 to 30 days, depending on the age and size of the animals [12-14].

Post metamorphosis, several anatomical alterations have been observed (Figure 1). To accommodate lung ventilation, Coleman \& Hessler [15] found: (1) lung volume increased to more than three times that of neotenous form; (2) lung wall thickness reduced by approximately one-third (as the surface area of the lumen increased); (3) there was approximately $12 \%$ increase in the length of the lung; and (4) many new small blood vessels vascularised the metamorphosed lung. These changes increase the effectiveness of oxygen and carbon dioxide gas exchange concomitant with lung-dependent respiration. Associated with these morphological changes in the respiratory organs are marked changes in the associated cardiovascular system, where the branchial arches supplying the gills regress and are replaced by internal and external carotid arteries [16].

The heart muscle shows an increase in trabeculation $[14,17]$ which seems appropriate for coping with the increase in metabolic demands of more musculature on terrestrially adapted limbs $[18,19]$ The neotenous heart has a "spongy" ventricle with less organized myofibrils (Figure 2 ). Since the neotenous axolotls have gills and can respire cutaneously too, it is not so important that the heart be as functionally effective as that of a metamorphosed axolotl. The metamorphosed axolotl becomes a committed lung breather and so would need a more robust pump to circulate oxygenated blood. Consequently, the metamorphosed heart shows more organized myofibrils and increased trabeculation in comparison with the neotenous salamander (Figure 2).

For these respiratory and cardiovascular changes to occur there must be some associated neurological changes too. It has been found that $18 \%$ of neurons from the dorsal vagal motonucleus (located in the medulla oblongata) migrate to a new ventrolateral position over the metamorphic course in axolotls [14]. Intriguingly, this migration of neurons was found to occur in human embryos and foetuses too $[20,21]$. It is hypothesised that this relocation could relate to the evolution of heart rate variability and that this region may be equivalent to a primitive form of the nucleus ambiguus found in higher organisms $[22,23]$. The nucleus ambiguus appears to be involved in respiratory and cardiac rhythms, whereas neurons found in the dorsal vagal motonucleus are not involved in the respiratory cycle [24]. Therefore, this ventrolateral location may be involved in the ontogeny and evolution of lung breathing (and/or its control).

\section{Gene Expression and Apoptosis in Metamorphic Axolotl Hearts}

The animal body undergoes rapid and dramatic changes during amphibian metamorphosis. Although a large body of data exists on changes induced in Xenopus during metamorphosis both at the physiological and molecular levels, little is known about urodeles with the exception of a few $[25,26]$, even though they offer the unique situation of controlled inducible metamorphosis. Changes occurring in Xenopus gut, liver, and skin are well characterized, but there are no reports of any changes occurring in the hearts of metamorphosing animals, including the axolotl.

We first reported a dramatic increase in the expression of HoxA5 gene in axolotl hearts as determined by RT-PCR and in situ hybridization during spontaneous metamorphosis [27]. Subsequently,

*Corresponding author: Dipak K Dube, Department of Medicine, SUNY Upstate Medical University, USA, Tel: 315 464-5440; E-mail: dubed@upstate.edu

Received December 17, 2013; Accepted December 18, 2013; Published December 26, 2013

Citation: Dube DK, Narshi A, McLean MD, Dube S, Poiesz BJ (2013) Gene Expression in Thyroxin-Induced Metamorphosing Axolotl Hearts. Cardiol Pharmaco 2: e122. doi:10.4172/2329-6607.1000e122

Copyright: $\odot 2013$ Dube DK, et al. This is an open-access article distributed under the terms of the Creative Commons Attribution License, which permits unrestricted use, distribution, and reproduction in any medium, provided the original author and source are credited. 


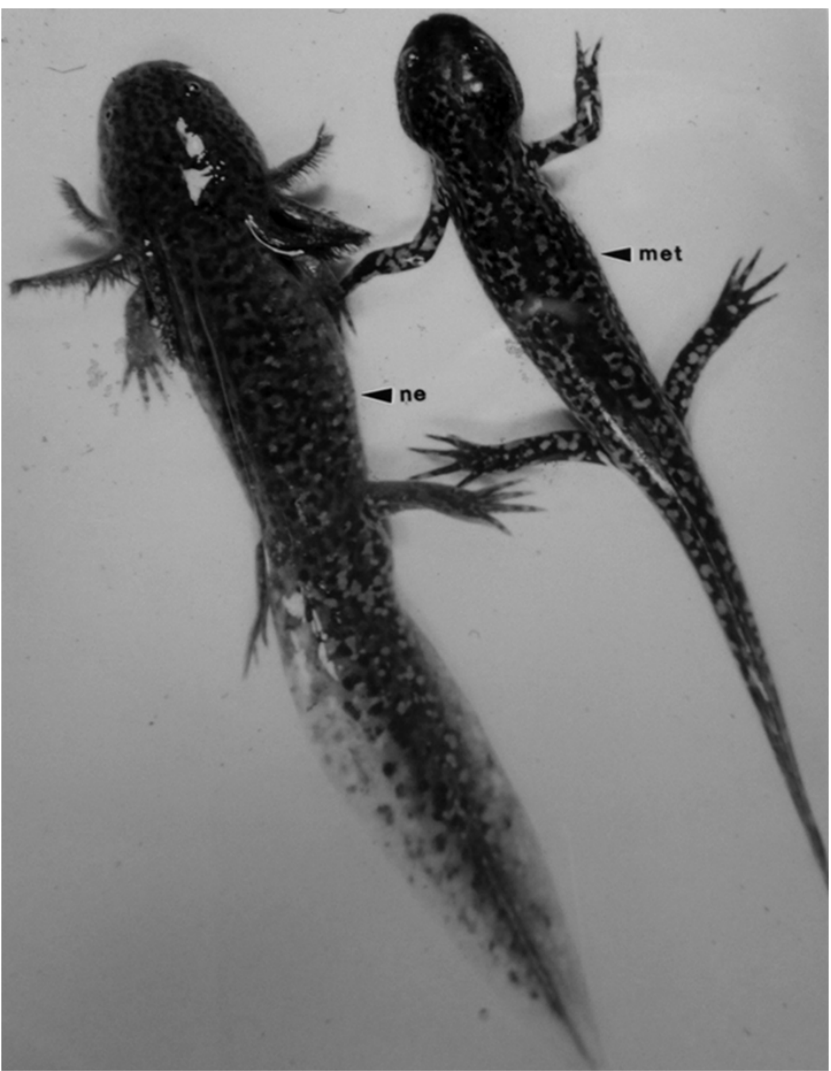

The metamorphosis was induced by injecting the animal with $25 \mathrm{mg}$ of thyroxin in Ringer's soulution per gram of body weight. The neotenous adult axolotls were injected with Ringer's solution [12].

Figure 1: Picture of neotenous (ne) adult axolotl alongside a completely metamorphosed (met) adult axolotl

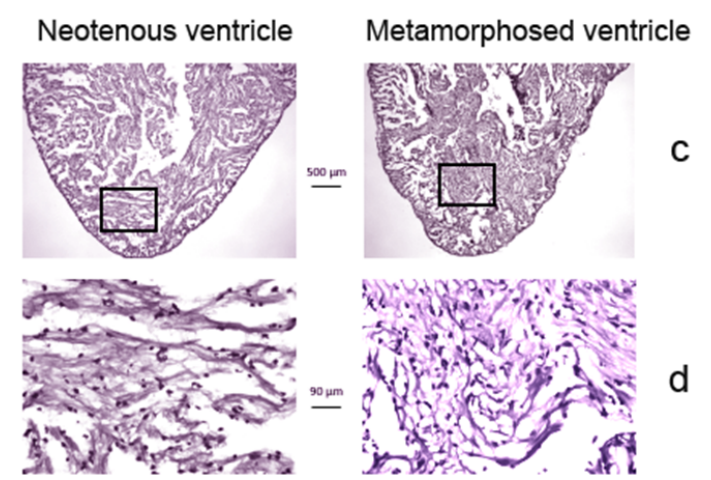

Boxed areas in the upper images are the enlarged sections in the lower images [14].

Figure 2 : Haematoxylin and eosin staining of neotenous \& metamorphosed axolotl hearts.

we studied the temporal and spatial expression pattern of HoxA5 in cardiac tissues during thyroxin-induced metamorphosis of the Mexican axolotl, and a similar increase in HoxA5 expression was found. The complete process of metamorphosis in the axolotl took 24-25 days. The transcript level of HoxA5 started to increase, compared to the control, at $4 \mathrm{~h}$ after thyroxin injection and plateaued by $48 \mathrm{~h}$. It returned to the normal/control level at day 28 after thyroxin injection. We performed in situ hybridization analyses for expression analyses of HoxA5 transcripts on sections from different regions of hearts from neotenous and thyroxin-induced metamorphosing axolotls. Staining for HoxA5 was seen in the cells of the epicardium but no staining was detected in the myocardium or endocardium. In contrast, the ventricle from a metamorphosing animal (at 16 day post thyroxin injection) showed a weak staining in the epicardium, and much more intense staining throughout the entire myocardium, but no signal in the endocardium. Confocal microscopic analyses of cryo-sections of hearts from control or metamorphic juvenile axolotls were performed after staining with HoxA5 antibody. It is to be noted that juvenile axolotls (2-3 inches long) undergo complete metamorphic changes at a much faster rate compared to adult animals. After thyroxin injection, it takes about 1518 days for the completion of the entire process of metamorphosis in juveniles. Immunohistochemical results showed no positive signal for HoxA5 in control hearts whereas there was a very weak signal of HoxA5 in day 3 post-injection hearts. At day 10 and day 14 (around halfway to three-quarters into the metamorphosis), there was a significant increase in HoxA5 protein expression in hearts of thyroxin injected juveniles. HoxA5 protein was localized to all sections of the $\mathrm{z}$-series in a diffuse pattern. Therefore, it appears that the process of metamorphosis induces the expression of HoxA5 in cardiac tissues, which is not seen in the neotenous hearts.

HoxA5 is a member of the Hox group of the homeobox genes. The Hox genes encode transcription factors that are involved in regulating body formation during development. In vertebrates there are four Hox gene clusters known as HoxA, HoxB, HoxC, and HoxD. HoxA5 is the member of HoxA cluster. Aubin et al [28] created HoxA5 homozygous mutant mice. Analysis of the new born homozygous mutants found improper trachea and lung morphogenesis, which strongly suggests that HoxA5 is involved in appropriate lung and trachea development $[29,30]$.

Hall et al. [29] identified common genes and signalling pathways whose expression was associated with reversal of heart failure and restoration of ventricular function in human patients with nonischaemic refractory heart failure after treating with a novel combination therapy. The combination therapy consisted of a left ventricular assist device (LVAD) combined with pharmacologic therapy including a selective 2-agonist. In the study, microarray analysis is using RNA samples taken at the time of the LVAD implant, and then at LVAD removal following recovery of ventricular function, was performed. They identified a total of 263 genes, which were significantly up- or down-regulated in the recovered hearts (paired T-test, $\mathrm{P}<0.01$ ). Amongst these genes, HoxA5 was found to be down-regulated 2.99 fold in recovery patients following combination therapy. Although the researchers noted the significant down regulation of HoxA5 expression during recovery, they did not discuss its significance. So the question still remains as to whether HoxA5 plays any significant role in heart failure.

In another study, Dewy et al. [30] using gene co-expression network analysis, defined the gene expression network topology of cardiac hypertrophy and failure, and the extent of recapitulation of fetal gene expression programs in failing and hypertrophied adult myocardium. They used unbiased marginal module analysis of gene co-expression networks from all murine myocardial transcript abundance data available in the published literature to formally evaluate the hypotheses that there are gene programs unique to fetal myocardium and these gene programs are re-capitulated in myocardial adaptation. The authors concluded that modules common to developing and failing myocardium were enriched in targets of HoxA5, a transcription factor 
with known roles in lung development in mammals and apoptotic heart morphogenesis in amphibians.

HoxA5 is known to act as a positive regulator for the p53 gene that protects cells against malignant transformation through apoptosis [31]. Apoptosis or programmed cell death is a genetically controlled response for cells to commit suicide. Disruption of apoptosis has been described as a fundamental pathogenic mechanism in a variety of human diseases including various cardiovascular diseases like myocardial infraction, heart failure, and atherosclerosis [32]. During metamorphosis, amphibians undergo remodelling of various organs [33]. Previously, we reported an increase of p53 expression in cardiac tissue in axolotls during metamorphosis after injecting thyroxin [13]. A significant up-regulation of HoxA5 [12] and p53 expression [13] suggest an increase in apoptosis via p53 in thyroxin-induced metamorphic axolotl hearts. Recently, we have evaluated the apoptosis in heart sections from control and thyroxin-induced metamorphosed axolotls by using CardioTACS ${ }^{\mathrm{TM}}$ In Situ Apoptosis Detection Kit (Trevigen). We found an approximate 3 -fold increase in apoptosis in sections from metamorphic animals compared to the control (unpublished Narshi and Dube). We hypothesize that thyroxin induces HoxA5, which in turn augments the expression of p53 gene and subsequently brings about higher levels of apoptosis in metamorphosing axolotl hearts.

Our gene expression studies over the years show that the expression of various homeobox genes like HoxA5 [12] and Nkx2.5 [13], -MyHC [34], and p53, undergo significant changes in T3-induced metamorphic axolotl hearts. Several sacromeric protein genes like tropomodulin and myosin binding protein $\mathrm{C}$ do not undergo significant modulation in metamorphic axolotls. T3, the active form of the thyroid hormone, serves as a ligand for its receptors, which are known as thyroid hormone receptors (TRs). There are two such receptors designated as TR $\alpha$ and TR. These receptors are nuclear transcription factors responsible for activating or repressing transcription of the genes containing thyroxin responsive elements (TRE) in a thyroxin-dependent manner [35]. Myosin heavy chain (MyHC) genes have TREs at their upstream regulatory regions [36]. Thyroid hormones upregulate $\alpha-\mathrm{MyHC}$, whereas - MyHC is down regulated. On the contrary, the mechanism by which HoxA5 without TRE at the upstream promoter region is upregulated in axolotl hearts during metamorphosis is not clear.

Wang and Shi [37] reported upregulation of thyroid receptor- $\alpha$ $(\mathrm{TR} \alpha)$ and retinoic acid receptor $(\mathrm{RxR} \alpha)$ in the tail during metamorphosis in frogs. RXR $\alpha$ alone does not activate the gene(s) containing retinoic acid responsive element (RARE) [38]. For its effective binding with DNA and subsequent activation of transcription, it requires the formation of a heterodimer with another closely related protein RXR. The heterodimer RXR $\alpha / \mathrm{RXR}$ is actually the effective inducer of the gene(s) with RARE [38]. It is unknown whether RXR is also induced along with RXR $\alpha$ in thyroid hormone induced metamorphosed frog tail [37]. If both RXR $\alpha$ and RXR are induced in metamorphic axolotl hearts, these receptors can form a heterodimer that subsequently activates the HoxA5 gene, which has RARE, but not TRE, at the upstream promoter region. The elevated level of HoxA5 protein may in turn induce $\mathrm{p} 53$-independent apoptosis in metamorphic axolotl hearts. In fact, Chen et al [39] reported that HoxA5 can act directly downstream of RAR and may contribute to retinoid-induced anticancer and chemo-preventive effects by inducing apoptosis in MCF10A breast cancer cells. As p53 expression is up regulated in metamorphosing axolotl hearts, HoxA5 may induce apoptosis by both p53 independent and dependent pathways.

The other possibility is that thyroxin may induce another protein, with or without homeobox, which in turn activates the HoxA5 gene in axolotl heart during metamorphosis. In fact, the relatively slow rate of induction of the HoxA 5 transcripts and its translational product, which takes several days after thyroxin treatment, strongly argues in favor of the involvement of some other intermediary regulatory protein(s) in the subsequent augmentation of HoxA5 in metamorphosing hearts [12].

\section{Concluding Remarks}

The axolotl is an apt animal model to study the ontogeny of heart rate variability and related neural changes, as it predominantly uses its gills when in the larval form, and upon metamorphosis, becomes a committed lung breather. The central nervous system is likely to undergo essential modifications in association with lung, and possibly heart, innervation and gill degeneration.

Many genes that are associated with molecular and morphological events during metamorphosis have been identified from studies of anurans, and in particular Xenopus laevis. In contrast, little is known about patterns of gene expression during salamander metamorphosis. Page et al [40] reported a detailed molecular analysis on the effect of thyroid hormone on gene expression in metamorphic axolotl using microarray analyses with RNA from control and metamorphic skins. However, to the best of our knowledge, no such analyses has been reported on metamorphosing and metamorphic axolotl hearts that may explain better the morphological as well molecular changes that have been observed. Such future studies might explain the higher level of apoptosis that we have observed in metamorphic axolotl hearts.

\section{Acknowledgement}

The work in this laboratory was supported by grants from American Heart Association (both National \& New York State affiliate), CNY Children's Miracl Network, Syracuse, NY, grants from Golisano Children's Hospital, Syracuse, NY, and funding from College of Health Professionals, Upstate Medical University, Syracuse to DKD and the Barbara Kopp Cancer Research Fund to BJP.

\section{References}

1. Humphrey RR (1972) Genetic and experimental studies on a mutant gene (c) determining absence of heart action in embryos of the Mexican axolotl (Ambystoma mexicanum). Dev Biol 27: 365-375.

2. Lemanski LF (1973) Morphology of developing heart in cardiac lethal mutant Mexican axolotls, Ambystoma mexicanum. Dev Biol 33: 312-333.

3. Lemanski LF (1979) Role of tropomyosin in actin filament formation in embryonic salamander heart cells. J Cell Biol 82: 227-238.

4. Zajdel RW, McLean MD, Lemanski SL, Muthuchamy M, Wieczorek DF, et al. (1998) Ectopic expression of tropomyosin promotes myofibrillogenesis in mutant axolotl hearts. Dev Dyn 213: 412-420.

5. Zajdel RW, Dube DK, Lemanski LF (1999) The cardiac mutant Mexican axolotl is a unique animal model for evaluation of cardiac myofibrillogenesis. Exp Cell Res 248: 557-566.

6. Zajdel RW, Sanger JM, Denz CR, Lee S, Dube S, et al. (2002) A novel striated tropomyosin incorporated into organized myofibrils of cardiomyocytes in cell and organ culture. FEBS Lett 520: 35-39.

7. Armstrong JB, Malacinski GM (1989) Developmental Biology of the Axolotl. Oxford University Press.

8. Bordzilovskaya N, Detlaff TA, Duhon S, Malacinski GM (1989) Developmentalstage series of axolotl embryos. In: Developmental Biology of the Axolotl. Oxford University Press, New York.

9. Rosenkilde P, Ussing AP (1996) What mechanisms control neoteny and regulate induced metamorphosis in urodeles? Int J Dev Biol 40: 665-673. 
Citation: Dube DK, Narshi A, McLean MD, Dube S, Poiesz BJ (2013) Gene Expression in Thyroxin-Induced Metamorphosing Axolotl Hearts. Cardiol Pharmacol 2: e122. doi:10.4172/2329-6607.1000e122

10. Norris DO, Platt JE (1973) Effects of pituitary hormones, melatonin, and thyroidal inhibitors on radioiodide uptake by the thyroid glands of larval and adult tiger salamanders, Ambystoma tigrinum (Amphibia: Caudata). Gen Comp Endocrinol 21: 368-376.

11. Taurog A (1974) Effect of TSH and long-acting thyroid stimulator on thyroid 131I-metabolism and metamorphosis of the Mexican axolotl (Ambystoma mexicanum). Gen Comp Endocrinol 24: 257-266

12. Gaur A, Zajdel RW, Bhatia R, Isitmangil G, Denz CR, et al. (2001) Expression of HoxA5 in the heart is upregulated during thyroxin-induced metamorphosis of the Mexican axolotl (Ambystoma mexicanum). Cardiovasc Toxicol 1: 225-235.

13. Thurston HL, Prayaga S, Thomas A, Guharoy V, Dube S, et al. (2009) Expression of Nkx2.5 in wild type, cardiac mutant, and thyroxine-induced metamorphosed hearts of the Mexican axolotl. Cardiovasc Toxicol 9: 13-20.

14. Narshi A (2011) the role of tropomyosin during heart development (Part I) and Neuroanatomical and cardiorespiratory changes associated with metamorphosis (Part II) in the axolotl, Ambystoma mexicanum. PhD Thesis, University of Birmingham, UK

15. Coleman CM, Hessler AC (1997) Thyroxin induced metamorphosis in a neotenic axolotl (Ambystoma mexicanum): gills, lungs, and capillaries. Axolotl Newsletters 26: 4-9.

16. Kolesová H, Lametschwandtner A, Rocek Z (2007) The evolution of amphibian metamorphosis: insights based on the transformation of the aortic arches of Pelobates fuscus (Anura). J Anat 210: 379-393.

17. Farmer CG (1999) Evolution of the vertebrate cardio-pulmonary system. Annu Rev Physiol 61: 573-592.

18. Chen H, Zhang W, Sun X, Yoshimoto M, Chen Z, et al. (2013) Fkbp1a controls ventricular myocardium trabeculation and compaction by regulating endocardial Notch1 activity. Development 140: 1946-1957.

19. Garita B, Jenkins MW, Han M, Zhou C, Vanauker M, et al. (2011) Blood flow dynamics of one cardiac cycle and relationship to mechanotransduction and trabeculation during heart looping. Am J Physiol Heart Circ Physiol 300: H879891.

20. Brown JW (1990) Prenatal development of the human nucleus ambiguus during the embryonic and early fetal periods. Am J Anat 189: 267-283.

21. Bennett JA, Kidd C, Latif AB, McWilliam PN (1981) A horseradish peroxidase study of vagal motoneurones with axons in cardiac and pulmonary branches of the cat and dog. Q J Exp Physiol 66: 145-154.

22. Hou L, Tang H, Chen Y, Wang L, Zhou X, et al. (2009) Presynaptic modulation of tonic and respiratory inputs to cardiovagal motoneurons by substance $P$. Brain Res 1284: 31-40.

23. Taylor EW (1994) The evolution of efferent vagal control of the heart in vertebrates. Cardioscience 5: 173-182.

24. Taylor EW, Leite CA, Skovgaard N (2010) Autonomic control of cardiorespiratory interactions in fish, amphibians and reptiles. Braz J Med Biol Res 43: 600-610.

25. Tata JR (2006) Amphibian metamorphosis as a model for the developmental actions of thyroid hormone. Mol Cell Endocrinol 246: 10-20.
26. Huggins $P$, Johnson CK, Schoergendorfer A, Putta S, Bathke AC, et al. (2012) Identification of differentially expressed thyroid hormone responsive genes from the brain of the Mexican Axolotl (Ambystoma mexicanum). Comp Biochem Physiol C Toxicol Pharmacol 155: 128-135.

27. Gaur A, Bhatia R, Spring-Mills E, Lemanski LF, Dube DK (1998) The heart of metamorphosing Mexican axolotl but not that of the cardiac mutant is associated with the upregulation of Hox A5. Biochem Biophys Res Commun 245: 746-751.

28. Aubin J, Lemieux M, Tremblay M, Bérard J, Jeannotte L (1997) Early postnata lethality in Hoxa-5 mutant mice is attributable to respiratory tract defects. Dev Biol 192: 432-445.

29. Hall JL, Birks EJ, Grindle S, Cullen ME, Barton PJ, et al (2007) Molecula signature of recovery following combination left ventricular assist device (LVAD) support and pharmacologic therapy. Eur Heart J 28: 613-627.

30. Dewey FE, Perez MV, Wheeler MT, Watt C, Spin J, et al. (2011) Gene coexpression network topology of cardiac development, hypertrophy, and failure. Circ Cardiovasc Genet 4: 26-35.

31. Raman V, Martensen SA, Reisman D, Evron E, Odenwald WF, et al. (2000) Compromised HOXA5 function can limit p53 expression in human breas tumours. Nature 405: 974-978.

32. van Empel VP, Bertrand AT, Hofstra L, Crijns HJ, Doevendans PA, et al. (2005) Myocyte apoptosis in heart failure. Cardiovasc Res 67: 21-29.

33. Ishizuya-Oka A, Hasebe T, Shi YB (2010) Apoptosis in amphibian organs during metamorphosis. Apoptosis 15: 350-364.

34. Ward SM (1995) Developmental and Molecular Analyses of C-Protein in Cardiac and Skeletal Muscle of Wildtype and Cardiac Non-function Mutant axolotls, Ambystoma mexicanum. PhD Thesis, SUNY Upstate Medical University, Syracuse, New York, USA.

35. Buchholz DR, Paul BD, Fu L, Shi YB (2006) Molecular and developmental analyses of thyroid hormone receptor function in Xenopus laevis, the African clawed frog. Gen Comp Endocrinol 145: 1-19.

36. Gustafson TA, Markham BE, Morkin E (1986) Effects of thyroid hormone on alpha-actin and myosin heavy chain gene expression in cardiac and skeletal muscles of the rat: measurement of mRNA content using synthetic oligonucleotide probes. Circ Res 59: 194-201.

37. Wong J, Shi YB (1995) Coordinated regulation of and transcriptional activation by Xenopus thyroid hormone and retinoid X receptors. J Biol Chem 270: 18479 18483.

38. Yu VC, Delsert C, Andersen B, Holloway JM, Devary OV, et al. (1991) RXR beta: a coregulator that enhances binding of retinoic acid, thyroid hormone, and vitamin D receptors to their cognate response elements. Cell 67: 1251-1266.

39. Chen $\mathrm{H}$, Zhang $\mathrm{H}$, Lee J, Liang X, Wu X, et al. (2007) HOXA5 acts directly downstream of retinoic acid receptor beta and contributes to retinoic acidinduced apoptosis and growth inhibition. Cancer Res 67: 8007-8013.

40. Page RB, Monaghan JR, Walker JA, Voss SR (2009) A model of transcriptiona and morphological changes during thyroid hormone-induced metamorphosis of the axolotl. Gen Comp Endocrinol 162: 219-232. 